\title{
The Dopamine/D1 Receptor Mediates the Phosphorylation and Inactivation of the Protein Tyrosine Phosphatase STEP via a PKA-Dependent Pathway
}

\author{
Surojit Paul, ${ }^{1}$ Gretchen L. Snyder, ${ }^{3}$ Hisayuki Yokakura, ${ }^{1}$ Marina R. Picciotto, ${ }^{2}$ Angus C. Nairn, ${ }^{3}$ and \\ Paul J. Lombroso' ${ }^{1}$ \\ ${ }^{1}$ The Child Study Center and the ${ }^{2}$ Department of Psychiatry, Yale University School of Medicine, New Haven, Connecticut \\ 06520, and ${ }^{3}$ Rockefeller University, New York, New York 10021
}

\begin{abstract}
The striatal-enriched protein tyrosine phosphatase (STEP) family is expressed within dopaminoceptive neurons of the CNS and is particularly enriched within the basal ganglia and related structures. Alternative splicing produces several isoforms that are found in a number of subcellular compartments, including postsynaptic densities of medium spiny neurons. The variants include STEP S1 $_{1}$, a membrane-associated protein, and STEP 46 , a cytosolic protein. The $\mathrm{C}$ terminals of these two isoforms are identical, whereas the N-terminal domain of STEP ${ }_{61}$ contains a novel 172 amino acid sequence that includes several structural motifs not present in STEP 46 . Amino acid sequencing revealed a number of potential phosphorylation sites in both STEP isoforms. Therefore, we investigated the role of phosphorylation in regulating STEP activity. Both STEP ${ }_{61}$ and STEP ${ }_{46}$ are phosphorylated on seryl residues by a cAMP-dependent protein kinase (PKA)-mediated pathway in striatal homogenates. The specific
\end{abstract}

residues phosphorylated in $\mathrm{STEP}_{61}$ were identified by sitedirected mutagenesis and tryptic phosphopeptide mapping as Ser160 and Ser221, whereas the major site of phosphorylation in STEP $_{46}$ was shown to be Ser49. Ser160 is located within the unique $\mathrm{N}$ terminal of STEP $_{61}$. Ser221 and Ser49 are equivalent residues present in $\mathrm{STEP}_{61}$ and $\mathrm{STEP}_{46}$, respectively, and are located at the center of the kinase-interacting motif that has been implicated in protein-protein interactions. Phosphorylation at this site decreases the activity of STEP in vitro by reducing its affinity for its substrate. In vivo studies using striatal slices demonstrated that the neurotransmitter dopamine leads to the phosphorylation of STEP via activation of D1 receptors and PKA.

Key words: protein tyrosine phosphatase; KIM domain; dopamine; dopamine $D 1$ receptor; cAMP-dependent PKA; STEP; striatum; basal ganglia; protein tyrosine kinase; signal transduction
Tyrosine phosphorylation plays a critical role in a large number of fundamental physiological processes (Hunter, 1998; Chernoff, 1999). To regulate these processes, a delicate balance exists between the level of phosphorylation caused by protein tyrosine kinases (PTKs) and the opposing actions of protein tyrosine phosphatases (PTPs) (Fischer et al., 1991; Walton and Dixon, 1993; Hunter, 1995; Tonks and Neel, 1996). Many studies have demonstrated high levels of PTKs and PTPs within the CNS (Cooke and Perlmutter, 1989; Wagner et al., 1991). Although more information is available regarding the function and regulation of PTKs in the CNS (Qu et al., 1990; Winslow et al., 1995; Chen and Leonard, 1996; Kohr and Seeburg, 1996; Desai et al., 1997; Smart, 1997; Lu et al., 1998), growing evidence suggests that PTPs also regulate key events in neuronal development and function (Naegele and Lombroso, 1994; Dutta and Stoker, 1998; Vactor, 1998). Determining whether PTPs are regulated by specific neurotransmitter systems in the brain is an important step in understanding the underlying signaling pathways.

To address these questions, we have investigated the role of phosphorylation in regulating the activity of a striatal-enriched protein tyrosine phosphatase (STEP) that is preferentially expressed in the basal ganglia and related structures (Lombroso et al., 1991, 1993; Boulanger et al., 1995). STEP family members are produced by alternative splicing, and both cytosolic and membrane-associated variants exist (Bult et al., 1996). In addition,

Received Jan. 10, 2000; revised May 3, 2000; accepted May 11, 2000.

This work was supported by the National Institutes of Health Grants NS 35989, MH 01527, and MH 52711 to P.J.L., DA 00436 to M.R.P., and MH 40899 to A.C.N. We thank Drs. Anton Bennett, Pietro DeCamilli, James Leckman, Janice Naegele, Michele Solimena, and Flora Vaccarino for their helpful comments on this manuscript.

Correspondence should be addressed to Dr. Paul Lombroso, Child Study Center, Room I-270, Yale University School of Medicine, 230 South Frontage Road, New Haven, CT 06520. E-mail: paul.lombroso@yale.edu.

Copyright (C) 2000 Society for Neuroscience $0270-6474 / 00 / 205630-09 \$ 15.00 / 0$ some STEP members are truncated isoforms that lack the catalytic phosphatase domain (Sharma et al., 1995). Further diversity among the STEP isoforms derives from either the absence or presence of specific amino acid motifs implicated in their subcellular localization, substrate specificity, and regulation of catalytic activity (Bult et al., 1997).

Medium spiny neurons, the predominant cell type in the striatum in which STEP is most abundant, receive two major sources of synaptic input: glutamatergic afferents from the cerebral cortex contact dendritic shafts and spines (Fonnum et al., 1981; Somogyi et al., 1981), and dopaminergic afferents from the midbrain synapse close to the glutamatergic contacts (Freund et al., 1984; Kotter, 1994). The proximity of these two synaptic inputs suggests a functional consequence, namely, the modulation of one neurotransmitter pathway by the other (Cepeda et al., 1993; Cepeda and Levine, 1998). The presence of STEP in the same subcellular compartment raised the possibility that it may regulate, or be itself regulated, by one of these neurotransmitter systems (Greengard et al., 1999).

Our results establish that dopamine stimulation of medium spiny neurons results in the phosphorylation of STEP via activation of D1 receptors and cAMP-dependent protein kinase (PKA). Two major sites on $\mathrm{STEP}_{61}$ and one major site on $\mathrm{STEP}_{46}$ are phosphorylated by PKA. Phosphopeptide mapping identified these sites as Ser160 and Ser221 in STEP 61 and Ser49 in STEP 46 . The physiological relevance of these results has been confirmed in striatal slice experiments in which STEP is phosphorylated at the identified sites in response to stimulation by dopamine or D1 agonists via a PKA-mediated pathway. The affinity of STEP for its substrate was dramatically decreased after phosphorylation. These findings, in conjunction with other studies, support a model in which STEP may play an important role in mediating the effects of dopamine on striatal medium spiny neurons. 


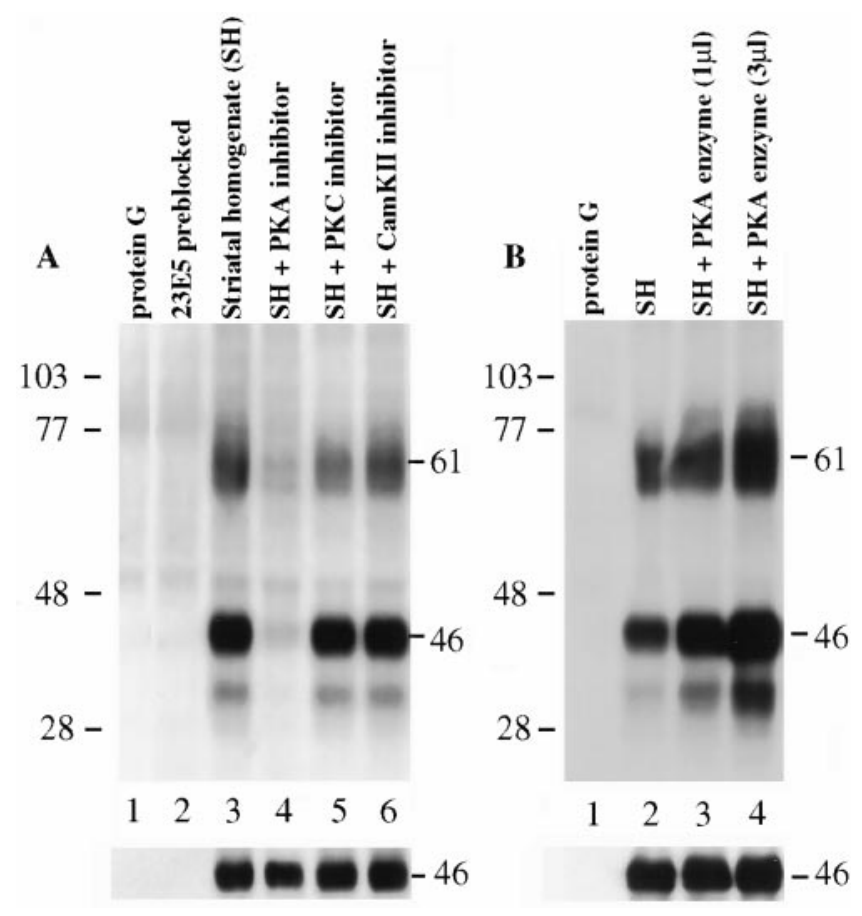

Figure 1. Phosphorylation of STEP isoforms in striatal homogenates. $A$, Effect of protein kinase inhibitors on the phosphorylation of STEP. Striatal homogenates from rat brain were phosphorylated with $\left[\gamma^{32} \mathrm{P}\right] \mathrm{ATP}$ using endogenous kinases in the absence (lane 3) or presence of the PKA inhibitor $(50 \mathrm{nM}$; lane 4$)$, PKC inhibitor $(1 \mu \mathrm{M}$; lane 5$)$, or CaMKII inhibitor $(0.4 \mu \mathrm{M}$; lane 6$)$. STEP isoforms were immunoprecipitated with a monoclonal antibody against STEP, 23E5, resolved by SDS-PAGE, transferred to a PVDF membrane, and subjected to autoradiography. The phosphorylated bands were identified as STEP ${ }_{61}$ and $\mathrm{STEP}_{46}$, respectively, by probing the membrane with 23E5. Controls included protein G-Sepharose alone (lane 1) and preabsorption of the monoclonal antibody with $10 \mu \mathrm{g}$ of the peptide immunogen (lane 2). B, Effect of PKA on the phosphorylation of STEP. The extent of phosphorylation of STEP isoforms by PKA $(0.65 \mu \mathrm{g} / \mu \mathrm{l})$ was assessed in the same way (lanes 3, 4). Controls included protein $\mathrm{G}$ alone (lane 1) and no added PKA (lane 2). The molecular mass standards are indicated in kilodaltons on the left. The numbers on the right indicate the protein bands corresponding to $\mathrm{STEP}_{61}$ and $\operatorname{STEP}_{46}$.

\section{MATERIALS AND METHODS}

Materials. Male Sprague Dawley rats (180-250 gm) were obtained from Charles River Laboratories (Wilmington, MA). The PKA catalytic subunit, PKA inhibitor (PKI- $\alpha$ ), protein kinase C (PKC) inhibitor peptide (19-36), $\mathrm{Ca}^{2+} /$ calmodulin-dependent protein kinase II (CaMKII) inhibitor, dopamine, forskolin, and the D1 agonist SKF-81297 were obtained from Calbiochem (La Jolla, CA). Anti-phosphotyrosine antibody was obtained from Upstate Biotechnology (Lake Placid, NY). Protein G-Sepharose and $\left[\gamma^{32} \mathrm{P}\right]$ ATP (specific activity $>5000 \mathrm{Ci} / \mathrm{mmol}$ ) were obtained from Pharmacia (Piscataway, NJ). $\left[{ }^{32} \mathrm{P}\right]$ orthophosphate was obtained from DuPont NEN (specific activity, 8500-9120 Ci/mmol; Boston, MA). The ECL detection kit was obtained from Pierce (Rockford, IL) Ouabain, phosphotyrosine, phosphoserine, phosphothreonine, Nonidet P-40 (NP-40), N-tosyl-L-phenylalanine chloromethyl ketone (TPCK)trypsin, and all other biochemicals were obtained from Sigma (St. Louis, MO) unless otherwise indicated.

Tissue preparation for in vitro phosphorylation. Male Sprague Dawley rats were decapitated, and the forebrains were rapidly removed and placed into ice-cold HEPES-buffered sucrose $(0.32 \mathrm{~m}$ sucrose, $4 \mathrm{~mm}$ HEPES, $50 \mathrm{~mm}$ $\mathrm{NaF}, 10 \mathrm{~mm}$ sodium pyrophosphate, $1 \mathrm{~mm}$ sodium vanadate, and a cocktail of protease inhibitors, pH 7.4) (Bult et al., 1996, 1997). The striatum was microdissected out and homogenized in 10 vol of ice-cold HEPESbuffered sucrose with 10 strokes in a glass Teflon homogenizer rotating at $1200 \mathrm{rpm}$. The homogenate was centrifuged at $800 \times g$ for $10 \mathrm{~min}$ at $4^{\circ} \mathrm{C}$ to remove nonhomogenized material.

In vitro phosphorylation of STEP and tyrosine phosphatase activity assay. In vitro phosphorylation of striatal homogenates by endogenous kinases was performed under the following standard conditions: $20 \mathrm{~mm}$ Tris- $\mathrm{HCl}$, $2 \mathrm{~mm} \mathrm{MnCl}$, $20 \mathrm{~mm} \mathrm{MgCl}, 1 \mathrm{~mm}$ ouabain, $50 \mathrm{~mm} \mathrm{NaF}, 10 \mathrm{~mm}$ sodium pyrophosphate, $1 \mathrm{~mm}$ sodium vanadate, $20 \mu \mathrm{M}\left[\gamma^{-32} \mathrm{P}\right]$ ATP $(1000 \mathrm{cpm} /$ $\mathrm{pmol}$ ), and $500 \mu \mathrm{g}$ of protein in a final volume of $200 \mu \mathrm{l}$. Reactions were initiated by addition of $\left[\gamma^{32} \mathrm{P}\right] \mathrm{ATP}$ and performed for $10 \mathrm{~min}$ at $30^{\circ} \mathrm{C}$ Samples were rapidly frozen in liquid nitrogen to stop the reaction, diluted with $5 \mathrm{vol}$ of RIPA buffer, and incubated at $4^{\circ} \mathrm{C}$ for $1 \mathrm{hr}$ with constant shaking followed by centrifugation at $12,000 \times g$ for $10 \mathrm{~min}$ at $4^{\circ} \mathrm{C}$. The supernatant was further processed for immunoprecipitation followed by immunoblotting and autoradiography, as described below. Some phosphorylation reactions were performed with the addition of the PKA inhibitor $(50 \mathrm{nM})$, PKC inhibitor $(1 \mu \mathrm{M})$, or CamKII inhibitor $(0.4 \mu \mathrm{M})$ or in the presence of the PKA catalytic subunit $(0.65 \mu \mathrm{g} / \mu \mathrm{l})$.

Wild-type and mutant constructs of the GST-STEP ${ }_{61}$ fusion protein were phosphorylated by PKA in a final volume of $45 \mu$ l containing $20 \mathrm{~mm}$ HEPES, pH 7.4, $10 \mathrm{~mm} \mathrm{MgCl} 2,1 \mathrm{~mm}$ DTT, $50 \mu \mathrm{M}\left[\gamma^{-32} \mathrm{P}\right] \mathrm{ATP}$ (specific activity, $100-1000 \mathrm{cpm} / \mathrm{pmol}$ ), and $0.01-0.1 \mu \mathrm{g}$ of PKA (depending on the substrate). Reactions were initiated by the addition of $\left[\gamma_{-}{ }^{32} \mathrm{P}\right] \mathrm{ATP}$, and the mixtures were incubated at $30^{\circ} \mathrm{C}$ for different amounts of time. The reactions were stopped by the addition of 5 vol of $20 \%$ trichloroacetic acid followed by the addition of $10 \mu \mathrm{g}$ of BSA as a carrier protein. The mixtures were then centrifuged at $12,000 \times g$ for $10 \mathrm{~min}$. The pellets were washed twice with $5 \%$ trichloroacetic acid and dissolved in $1 \mathrm{ml}$ of $1 \mathrm{~N} \mathrm{NaOH}$ before quantification of Cerenkov radiation. In some experiments, reactions were terminated by adding SDS sample buffer, and the extent of phosphorylation was then assessed after SDS-PAGE and autoradiography. Nonradioactive phosphorylation of $\mathrm{STEP}_{46}$, for subsequent assays of enzymatic activity, was performed under identical conditions using nonlabeled ATP. These reactions were terminated at different time points by the addition of the PKA inhibitor PKI- $\alpha$. Enzyme activity assays were performed, using tyrosine-phosphorylated ${ }^{32} \mathrm{P}$-labeled myelin basic protein (MBP; PTP assay kit from New England Biolabs, Beverly, MA), according to the manufacturer's protocol.

${ }^{32}$ P labeling of striatal slices. Striatal slices from male Sprague Dawley rats (8-12 weeks of age) were prepared as described previously (Snyder et al., 1998). Four hundred micrometer sections of the brain were cut at $4^{\circ} \mathrm{C}$ on a vibratome and chilled in oxygenated, phosphate-free Krebs' bicarbonate buffer containing $125 \mathrm{~mm} \mathrm{NaCl}, 4 \mathrm{mM} \mathrm{KCl}, 26 \mathrm{mM} \mathrm{NaHCO}_{3}, 0.5 \mathrm{~mm}$ EGTA, $2 \mathrm{~mm} \mathrm{MgSO}_{4}$, and $10 \mathrm{~mm}$ glucose, $\mathrm{pH}$ 7.4. Slices of the neostriatum were dissected and individually incubated at $30^{\circ} \mathrm{C}$ in tubes saturated with a $95 \% \mathrm{O}_{2}, 5 \% \mathrm{CO}_{2}$ mix. After $15 \mathrm{~min}$ the buffer was replaced with fresh phosphate-free buffer containing $2.0 \mathrm{mCi}$ of $\left[{ }^{32} \mathrm{P}\right]$ orthophosphoric acid and incubated for $60 \mathrm{~min}$. The labeling buffer was then removed, and the tissue sections were rinsed twice with fresh buffer. The tissues were then incubated in Krebs' buffer in the absence or presence of forskolin $(50 \mu \mathrm{M})$ dopamine $(100 \mu \mathrm{M})$, the D1 receptor agonist SKF-81297 $(1 \mu \mathrm{M})$, or the D2 receptor agonist quinpirole $(1 \mu \mathrm{M})$ for the indicated time periods. In some experiments slices were preincubated with the D1 receptor antagonist SCH-23390 $(1 \mu \mathrm{M})$, the PKA inhibitor H-89 $(1 \mu \mathrm{M})$, or the PKC inhibitor calphostin $\mathrm{C}(1 \mu \mathrm{M})$ before treatment with specific neuromodulators. At the end of the incubation, the buffer was rapidly aspirated, and the tissue slices were immediately frozen in liquid nitrogen and stored at $-80^{\circ} \mathrm{C}$ until assayed.

Immunoprecipitation of $\left[{ }^{32} P\right]$ phosphate-labeled STEP. $\left[{ }^{32} \mathrm{P}\right]$ phosphatelabeled samples were first precleared with protein G-Sepharose and then incubated overnight at $4^{\circ} \mathrm{C}$ with $5-10 \mu \mathrm{g}$ of $23 \mathrm{E} 5$, a monoclonal antibody that recognizes all previously characterized isoforms of STEP (Boulanger et al., 1995). Immune complexes were then incubated with $50 \mu \mathrm{l}$ of protein G-Sepharose for $3 \mathrm{hr}$ at $4^{\circ} \mathrm{C}$. Beads were collected by centrifugation at $1000 \times g$ for 2 min and washed five times with NP-40-containing lysis buffer, and the protein was eluted with SDS sample buffer (Laemmli, 1970). The recovered proteins were then resolved by SDS-PAGE and transferred to a polyvinylidene difluoride membrane (PVDF) followed by autoradiography and immunoblot analysis. For striatal slices, immunoprecipitated STEP isoforms were resolved by SDS-PAGE and dried, and ${ }^{32} \mathrm{P}$ ]phosphate incorporation was quantified using a PhosphorImager $400 \mathrm{~B}$ and ImageQuant software from Molecular Dynamics (Sunnyvale, $\mathrm{CA}$. Values for $\left.{ }^{32} \mathrm{P}\right]$ phosphate content were normalized for the total ${ }^{32} \mathrm{P}$ ]phosphate incorporated into TCA-precipitable protein.

Phosphopeptide mapping and phosphoamino acid analysis. After SDSPAGE and autoradiography, gel pieces containing ${ }^{32} \mathrm{P}$-labeled STEP isoforms were incubated for $16 \mathrm{hr}$ with $50 \mu \mathrm{g} / \mathrm{ml}$ trypsin in $1 \mathrm{ml}$ of $50 \mathrm{~mm}$ $\mathrm{NH}_{4} \mathrm{HCO}_{3}$, and the supernatants containing the soluble phosphopeptides were recovered after centrifugation. ${ }^{32} \mathrm{P}$ was quantified by Cerenkov counting of the gel pieces and supernatants before and after digestion (extraction efficiency was consistently $>80 \%$ ). Two-dimensional phosphopeptide mapping and phosphoamino acid analysis were performed as described previously (Nairn and Greengard, 1987). For phosphopeptide mapping, electrophoretic separation was at $\mathrm{pH} 3.5$ for $90 \mathrm{~min}$ at $400 \mathrm{~V}$, and ascending chromatography was in pyridine/1-butanol/acetic acid/water $(10: 15: 3: 12)$. The pattern of tryptic phosphopeptides was detected by autoradiography or PhosphorImager analysis.

Site-directed mutagenesis and purification of the GST fusion protein. Point mutations were introduced into the STEP fusion protein cDNAs at serine residues identified by consensus sequences as potential sites for phosphorylation by PKA. This was accomplished by PCR-based site-directed mutagenesis using PfuTurbo DNA polymerase (Stratagene, La Jolla, CA) according to the manufacturer's protocol, and all mutations were verified by sequencing. Expression vectors (pGEX2T; Pharmacia) containing the wild-type or mutated cDNAs were transformed into Escherichia coli, BL21 for a high level of expression of the respective fusion protein. They were then purified according to the manufacturer's protocol. 

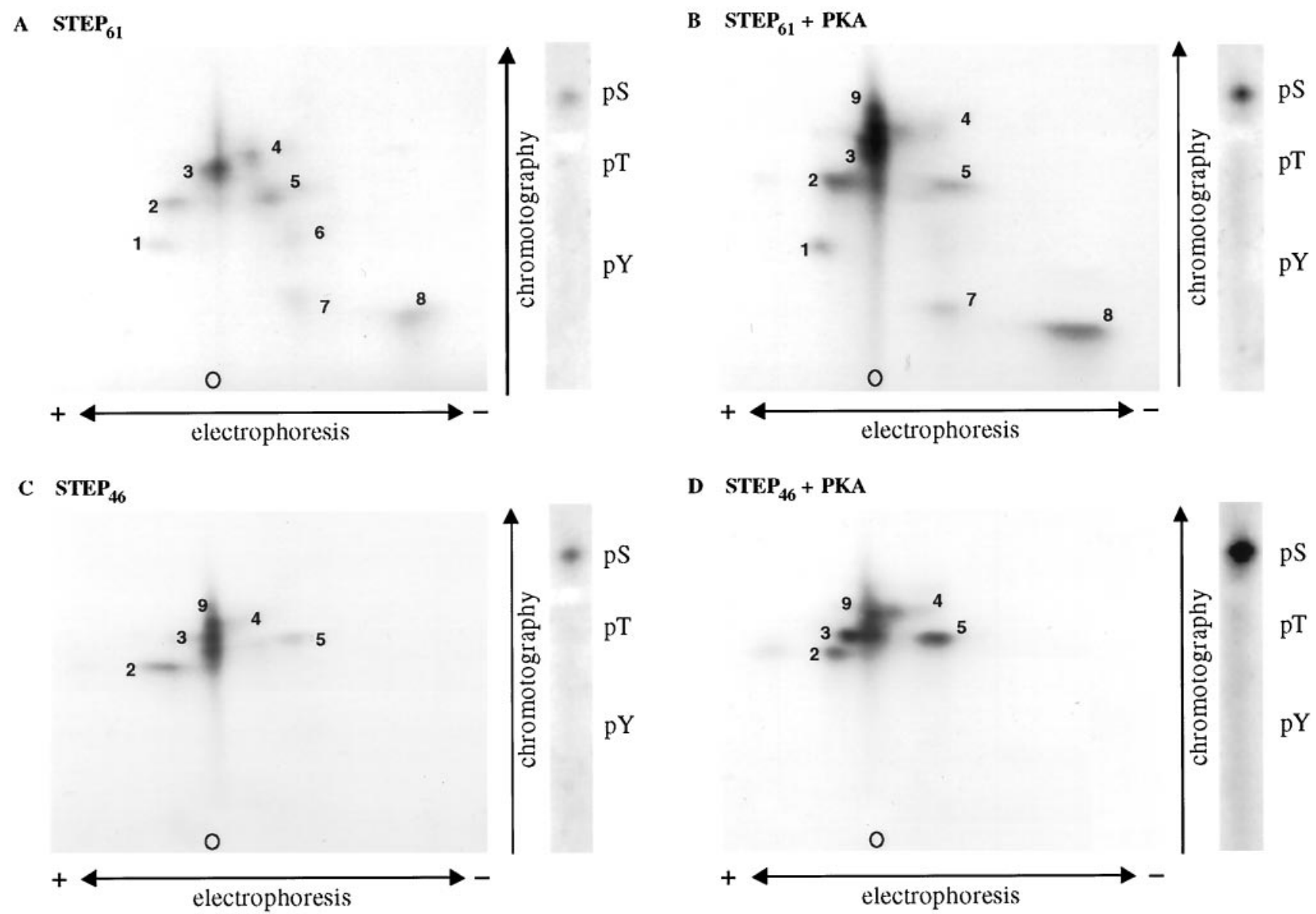
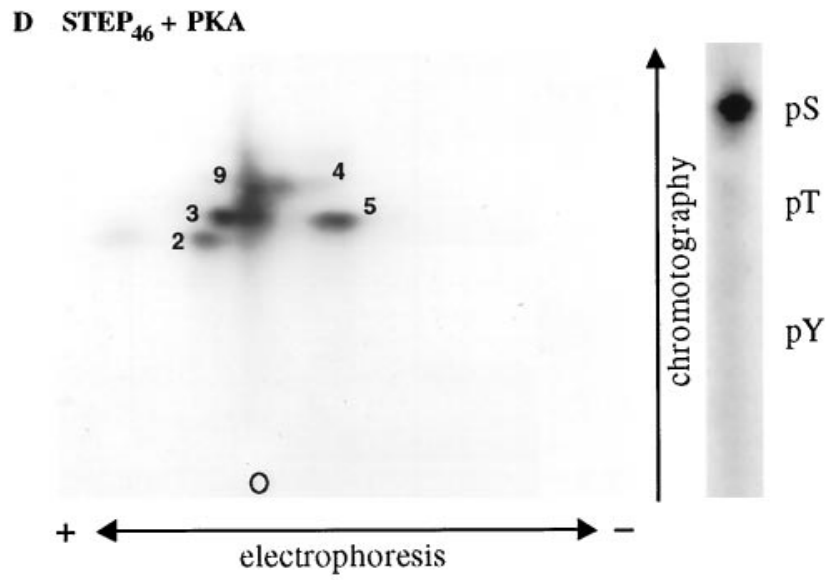

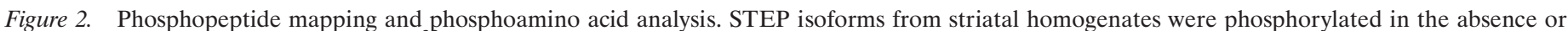

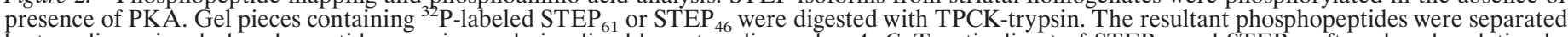

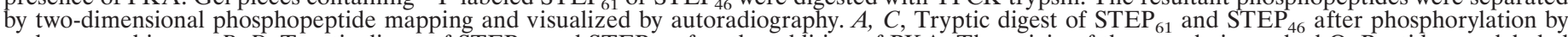

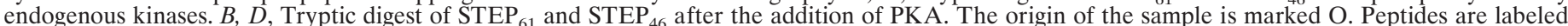

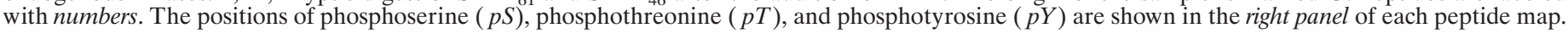

\section{RESULTS}

\section{Endogenous kinases phosphorylate STEP in striatal homogenates}

An initial series of experiments determined that STEP isoforms could be phosphorylated by endogenous striatal kinases (Fig. $1 \mathrm{~A}$, lane 3). Striatal homogenates were incubated in the presence of $\left[\gamma_{-}{ }^{32} \mathrm{P}\right] \mathrm{ATP}$, and STEP isoforms were immunoprecipitated using an anti-STEP antibody and separated by SDS-PAGE. Two labeled proteins of approximate molecular weights of 61 and $46 \mathrm{kDa}$ were detected by autoradiography. Immunoblot analysis identified them as $\mathrm{STEP}_{61}$ and $\mathrm{STEP}_{46}$, respectively. The quantity of STEP isoforms immunoprecipitated was similar for each lane (Fig. $1 A$, bottom row). The same membrane was stripped and reprobed with an anti-phosphotyrosine antibody (data not shown). The absence of tyrosine phosphorylation suggested that under these conditions STEP isoforms are phosphorylated on serine or threonine residues.

\section{PKA phosphorylates STEP isoforms}

The three major serine/threonine kinases present in medium spiny neurons that have been shown to respond to dopaminergic and/or glutamatergic inputs are PKA, PKC, and multifunctional CaMKII. To determine whether any of these kinases could phosphorylate STEP, striatal homogenates were incubated in the absence or presence of specific inhibitors of PKA, PKC, or CaMKII. STEP isoforms were then immunoprecipitated using STEP antibody and analyzed by SDS-PAGE and autoradiography. The PKA inhibitor PKI- $\alpha$ dramatically reduced the phosphorylation of both
STEP $_{61}$ and $\operatorname{STEP}_{46}$ (Fig. $1 A$, lane 4 ). On the other hand, the PKC inhibitor peptide or CaMKII inhibitor had little or no effect on the phosphorylation of STEP isoforms under the present experimental condition (Fig. $1 A$, lanes 5,6 ).

To clarify further the role of PKA in phosphorylating STEP, striatal homogenates were phosphorylated in the absence or presence of exogenous PKA. There was a significant increase in the phosphorylation of $\mathrm{STEP}_{61}$ and $\mathrm{STEP}_{46}$ in the presence of PKA compared with basal phosphorylation levels (Fig. 1B). Moreover, there was a concentration-dependent increase in the phosphorylation of both isoforms (Fig. 1B, lanes 3, 4).

Two-dimensional tryptic phosphopeptide mapping was used to characterize further the phosphorylation of $\mathrm{STEP}_{61}$ and $\mathrm{STEP}_{46}$ immunoprecipitated from striatal homogenates (Fig. 2). Several phosphopeptides were detected in $\mathrm{STEP}_{61}$, and the addition of PKA led to a significant increase in the phosphorylation of some of these peptides (Fig. 2, compare $A, B$ ). Similarly, multiple phosphopeptides were detected in $\mathrm{STEP}_{46}$, and PKA significantly increased the phosphorylation of these peptides (Fig. 2, compare $C$, $D)$. Phosphoamino acid analysis indicated that both isoforms were exclusively phosphorylated on seryl residues (Fig. 2, right panels).

A comparison of the phosphopeptide maps from STEP $_{61}$ and STEP $_{46}$ showed that they were partially identical, suggesting the presence of a common site(s) in both STEP isoforms. However, three major spots appear in $\mathrm{STEP}_{61}$ that are not detected in STEP $_{46}$ (Fig. 2A,B, spots 1, 7, 8). These results suggest that an additional phosphorylation site(s) is present within the unique $\mathrm{N}$-terminal domain of $\mathrm{STEP}_{61}$. 


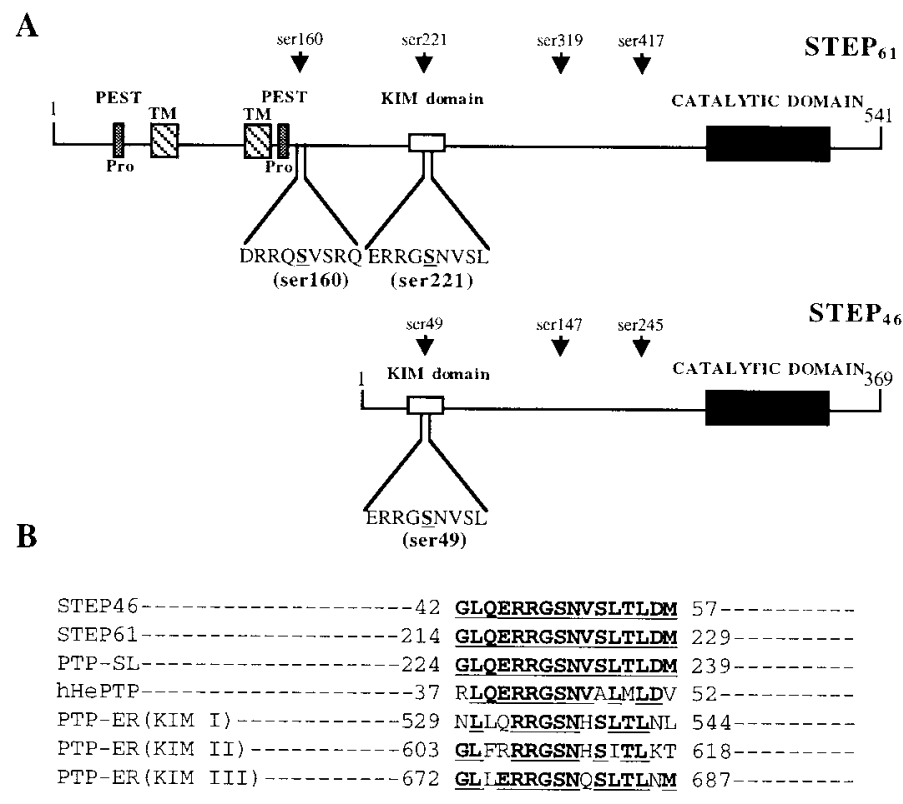

Figure 3. Comparison of $\mathrm{STEP}_{61}$ and $\mathrm{STEP}_{46} . A$, A schematic diagram of STEP $_{61}$ and STEP 46 indicating the positions of the catalytic domain, PEST sequences, transmembrane domains (TMs), polyproline-rich regions (Pro), and the kinase-interacting motif (KIM domain). The arrows indicate the positions of the potential PKA phosphorylation sites in both of the isoforms. Also shown are the sequences surrounding the major PKA phosphorylation sites in STEP 61 (Ser160 and Ser221) and STEP ${ }_{46}$ (Ser49). The phosphorylated serine residues are underlined. Note the location of Ser221 in STEP ${ }_{61}$ and Ser49 in STEP 46 within the KIM domain. $B$, Alignment of the KIM domains of STEP (residues 42-57), STEP $_{61}$ (residues 214-229), PTP-SL (residues 224-239), hHePTP (37-52), and PTP-ER (residues 529-544, 603-618, and 672-687). The conserved residues are in bold and underlined.

\section{Identification of the PKA phosphorylation sites on

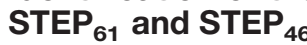

A schematic diagram of both $\mathrm{STEP}_{61}$ and $\mathrm{STEP}_{46}$ is shown in Figure $3 A$. STEP 61 contains a novel 172 amino acid sequence toward its $\mathrm{N}$ terminal that is not present in $\mathrm{STEP}_{46}$ because of alternative splicing, whereas the $\mathrm{C}$-terminal halves of the two proteins are identical. The several unique domains present in STEP $_{61}$ include two transmembrane domains, two PEST sequences, and two polyproline domains. Domains shared by both isoforms include the kinase-interacting motif (KIM) domain and the phosphatase domain. Several serine residues within consensus PKA sequences are found in both STEP variants, and the positions of these sites are indicated in Figure 3.

To test which of these residues could serve as PKA sites, several fusion proteins were made with each specific serine converted to alanine. Wild-type STEP $_{61}$ and STEP $_{46}$ fusion proteins as well as their respective mutants were purified to homogeneity and tested for their ability to be phosphorylated in vitro. Phosphorylation of STEP $_{61}$ caused a retardation in its electrophoretic mobility on SDS-PAGE, whereas phosphorylation of STEP $_{46}$ had no effect on the mobility of the protein band (data not shown). Mutation at Ser160 in STEP 61 abolished the shift in its mobility when phosphorylated (Fig. 4A, lane 2). However PKA was still able to phosphorylate the protein, suggesting the presence of an additional PKA-sensitive phosphorylation site(s) in $\mathrm{STEP}_{61}$. Mutations at the other sites in $\mathrm{STEP}_{61}$ had no detectable effect on phosphorylation level (Fig. 4A, lanes 3-5). In contrast, mutation at Ser49 in $\mathrm{STEP}_{46}$ resulted in an almost total loss of PKA phosphorylation (Fig. $4 B$, lane 2).

Tryptic phosphopeptide maps of the wild-type and mutant forms of STEP 61 and STEP $_{46}$ were generated to characterize further the sites of phosphorylation by PKA (Fig. 5). The pattern of the phosphopeptide maps of the wild-type fusion proteins was almost identical to that of the peptide maps obtained from endogenous
A
GST-STEP $_{61}$

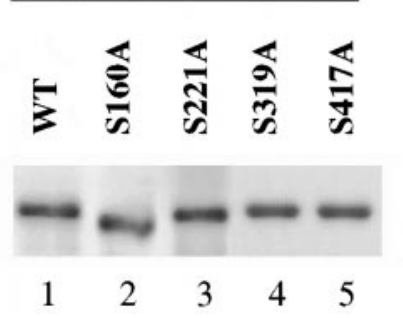

B
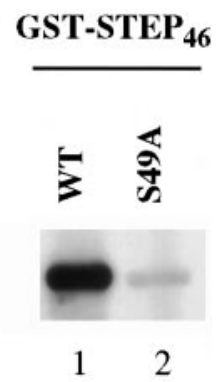

Figure 4. Phosphorylation of STEP fusion proteins by PKA. GST fusion proteins of $\mathrm{STEP}_{61}, \mathrm{STEP}_{46}$, and their mutants $(1 \mu \mathrm{g}$ of each) were phosphorylated by PKA using $\left[\gamma^{-32} \mathrm{P}\right] \mathrm{ATP}$ as described in Materials and Methods. The extent of phosphorylation was assessed after SDS-PAGE and autoradiography. $A$, GST-STEP 61 and its mutants. $B$, GST-STEP ${ }_{46}$ and its mutant. $W T$, Wild type.

STEP isoforms (compare Figs. 2, 5). Phosphopeptide maps of the mutant forms of $\mathrm{STEP}_{61}$ revealed that mutation at Ser160 or Ser221 led to a loss of phosphorylation of specific peptides (Fig. $5 B, C)$. Mutation at Ser49 in $\mathrm{STEP}_{46}$ led to a total loss of phosphorylation of all the major peptides (Fig. $5 E$ ). However, mutation of the other potential phosphorylation sites had no effect on the pattern of peptide maps in either isoform (data not shown). The data also indicate that in $\mathrm{STEP}_{61}$ peptides 1,7 , and 8 were derived by alternative cleavage of multiple tryptic sites flanking Ser160. Peptides 3, 4, and 9 in $\mathrm{STEP}_{61}$ and $\mathrm{STEP}_{46}$ were generated by alternative tryptic cleavage of amino acids flanking Ser221 and Ser49, respectively.

To analyze the time course of phosphorylation, recombinant STEP $_{61}$ and STEP $_{46}$ were incubated with PKA for various time periods in the presence of $\left[\gamma^{-32} \mathrm{P}\right] \mathrm{ATP}$. As measured by ${ }^{32} \mathrm{P}$ incorporation, phosphorylation proceeded in a time-dependent manner, reaching a maximal stoichiometry of $0.5 \mathrm{~mol} / \mathrm{mol}$ for $\mathrm{STEP}_{61}$ in 60 min (Fig. $6 A$ ) and $0.9 \mathrm{~mol} / \mathrm{mol}$ for $\mathrm{STEP}_{46}$ within $10 \mathrm{~min}$ (Fig. $6 B$, top). STEP $_{46}$ has an apparent $K_{\mathrm{m}}$ of $3.5 \mu \mathrm{M}$ and a $\mathrm{V}_{\max }$ of 11.4 $\mu \mathrm{mol} \cdot \mathrm{min}^{-1} \cdot \mathrm{mg}^{-1}$, suggesting that it is a very good substrate for PKA in vitro. STEP $_{61}$ has a $K_{\mathrm{m}}$ of $2.9 \mu \mathrm{M}$ and a $\mathrm{V}_{\max }$ of 0.27 $\mu \mathrm{mol} \cdot \mathrm{min}^{-1} \cdot \mathrm{mg}^{-1}$. $\mathrm{STEP}_{61}$ has two PKA sites, and higher stoichiometry values were expected. Increasing the time of phosphorylation, the amount of kinase, or the ATP concentration did not produce a significant increase in stoichiometry. One possible explanation for these results is that the binding of PKA to one of the sites sterically restricts the phosphorylation at the other site. We reasoned that mutation of any one of the PKA sites in $\mathrm{STEP}_{61}$ would lead to the complete phosphorylation at the other site. We therefore studied the kinetic parameters and stoichiometry of phosphorylation of the respective mutants. The results indicate that the molar ratio of phosphate incorporation for both mutants was still in the substoichiometric range (S160A mutant, $0.28 \mathrm{~mol} / \mathrm{mol}$; S221A mutant, $0.54 \mathrm{~mol} / \mathrm{mol}$ ).

\section{PKA phosphorylation of STEP inhibits enzyme activity}

We next determined the effect of PKA phosphorylation on the enzymatic activity of STEP. Two parallel reactions were performed. In the first reaction, $\mathrm{STEP}_{46}$ was phosphorylated by PKA in the presence of $\left[\gamma_{-}{ }^{32} \mathrm{P}\right] \mathrm{ATP}$ to analyze the time course of phosphorylation (Fig. $6 B$, top). In the second reaction, $\mathrm{STEP}_{46}$ was incubated with PKA for varying times $(0,1,2,3,5$, and $10 \mathrm{~min})$ using unlabeled ATP. At each time point, PKA activity was terminated, and the activity of $\mathrm{STEP}_{46}$ was measured in a second assay using tyrosine-phosphorylated MBP as substrate (Fig. 6B, bottom). The time course of phosphorylation of $\mathrm{STEP}_{46}$ by PKA was similar to that of the inhibition of enzyme activity (Fig. 6B). There was a $60 \%$ decrease in $\mathrm{STEP}_{46}$ activity after phosphorylation. In the control experiment, ATP was omitted during the initial phosphorylation, and there was little change measured in $\mathrm{STEP}_{46}$ activity. 
A $\quad$ GST-STEP $61+$ PKA

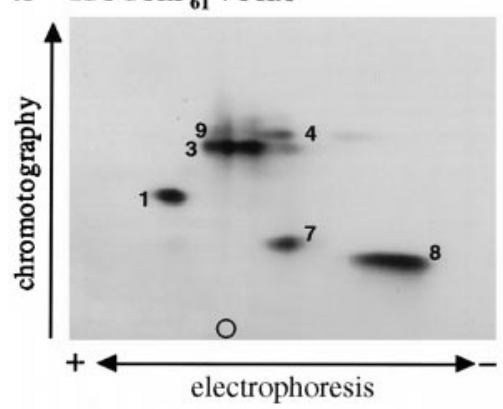

B GST-STEP $61($ S160A $)+$ PKA

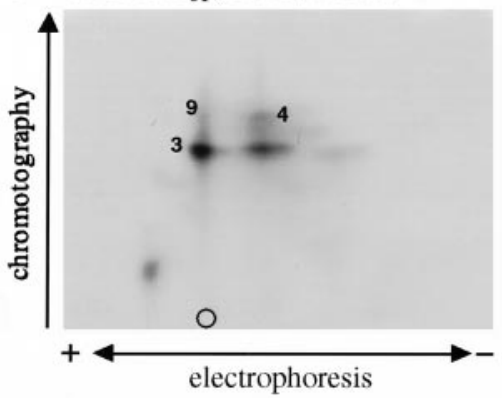

C GST-STEP 61 (S221A) + PKA

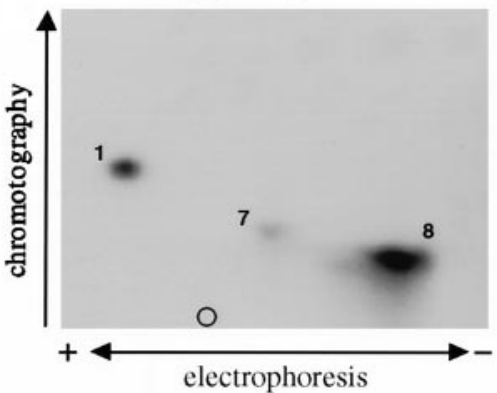

D GST-STEP ${ }_{46}+$ PKA

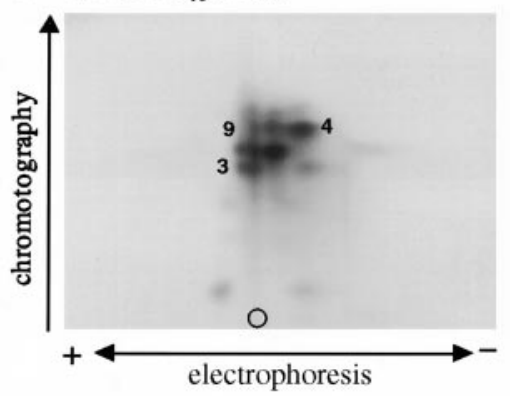

E GST-STEP 46 (S49A) + PKA

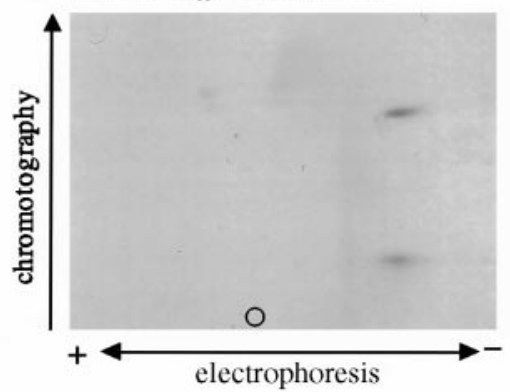

Figure 5. Ser160 and Ser221 in STEP61 and Ser49 in STEP46 are major sites of PKA phosphorylation in vitro. GST fusion proteins of STEP 61 , STEP $_{46}$, and certain mutated STEP variants were phosphorylated by PKA and analyzed by two-dimensional phosphopeptide mapping. $A$, Wild-type STEP $_{61}$. $B$, $\mathrm{STEP}_{61}, \mathrm{~S} 160 \mathrm{~A}$ mutation. $C, \mathrm{STEP}_{61}, \mathrm{~S} 221 \mathrm{~A}$ mutation. $D$, Wild-type $\mathrm{STEP}_{46} . E, \mathrm{STEP}_{46}, \mathrm{~S} 49 \mathrm{~A}$ mutation. For STEP 61 , analysis of the peptide maps suggests that peptides 1,7 , and 8 derive from alternative cleavage of multiple tryptic sites surrounding Ser160. Peptides 3 , 4, and 9 derive from alternative tryptic digestion of amino acids surrounding Ser221 in STEP $_{61}$ and Ser49 in STEP 46 .

Kinetic parameters of enzymatic activity of nonphosphorylated $\mathrm{STEP}_{46}$ and maximally phosphorylated $\mathrm{STEP}_{46}$ revealed that its apparent $K_{\mathrm{m}}$ increased by $\sim 65 \%$ (from 1.7 to $2.8 \mu \mathrm{M}$ ) after phosphorylation by PKA, whereas the $\mathrm{V}_{\max }$ was essentially unchanged (Fig. 7). Thus, inhibition of the enzymatic activity of STEP $_{46}$ after phosphorylation by PKA is caused by a reduction in its affinity for the substrate.

\section{Activators of PKA increase the phosphorylation of STEP $_{61}$ and STEP $_{46}$ in striatal slices}

To establish a physiological relevance for these findings, we wanted to identify the signaling cascade that leads to the phosphorylation of the STEP isoforms in vivo. Rat striatal slices were labeled with $\left[{ }^{32} \mathrm{P}\right]$ orthophosphate in the absence or presence of forskolin, an activator of PKA, followed by immunoprecipitation with antiSTEP monoclonal antibody and SDS-PAGE analysis. In untreated slices a low level of basal phosphorylation was detected in both STEP $_{61}$ and STEP $_{46}$, and incubation with forskolin led to a significant increase in the phosphorylation of both isoforms (Fig. $8 \mathrm{~A}$, lanes 1, 2). Incubation of striatal slices with 1,9-dideoxy forskolin (an inactive form of forskolin), under similar conditions, had no effect on the phosphorylation of STEP isoforms (data not shown).

Two-dimensional peptide maps were generated from STEP isoforms obtained from striatal slices treated with forskolin (Fig. $8 B, C)$. The peptide maps suggest that the same sites are phosphorylated in vivo and in vitro. Again, there appear to be two phosphorylation sites in $\mathrm{STEP}_{61}$ and one phosphorylation site in $\mathrm{STEP}_{46}$. On the basis of these results, we can conclude that in the striatum activation of PKA leads to a significant increase in the phosphorylation of Ser160 and Ser221 in $\mathrm{STEP}_{61}$ and Ser49 in $\mathrm{STEP}_{46}$.

\section{Dopamine stimulates the phosphorylation of STEP 61 and STEP 46}

Treatment of striatal slices with the neurotransmitter dopamine also increased the $\left[{ }^{32} \mathrm{P}\right]$ phosphate content of immunoprecipitated STEP $_{61}$ and STEP $_{46}$ by approximately 2- and 3.5 -fold, respectively, within 2.5 min of stimulation (Fig. $9 A$, lane 3 ); these levels began to decrease by $5 \mathrm{~min}$ (Fig. 9A, lane 4 ) and returned to near basal levels after 10 min of incubation (data not shown).

We next determined which of the two major subclasses of dopamine receptors, D1 or D2, was responsible for the observed phosphorylation pattern. Incubation of striatal slices with the D1-type dopamine receptor agonist SKF-81297 increased the phosphorylation of both $\mathrm{STEP}_{61}$ (2.5-fold) and $\mathrm{STEP}_{46}$ (3-fold) significantly (Fig. 9A, lane 6 ). In contrast, the $\mathrm{D} 2$ receptor agonist quinpirole has no detectable effect on the phosphorylation state of the STEP isoforms under the same conditions (Fig. 9A, lane 7). Preincubation of the striatal slices with the D1 receptor antagonist SCH-23390 blocked both dopamine- and SKF-81297 (D1 receptor agonist)mediated increases in the phosphorylation of the STEP isoforms (Fig. 9B, lanes 3, 6, respectively). These results strongly suggest that the neurotransmitter dopamine modulates the phosphorylation of STEP isoforms via the activation of a D1 receptor/cAMPdependent protein kinase pathway.

Selective protein kinase inhibitors were used to characterize further the kinase mediating the phosphorylation of STEP by the dopamine/D1 receptor pathway. Incubation of striatal slices with H-89, a cell-permeable inhibitor of PKA, had no effect on the basal phosphorylation level of the STEP isoforms (Fig. 10, lane 3). However, preincubation with $\mathrm{H}-89$ abolished the increase in the phosphorylation of STEP isoforms induced by treatment with the D1 receptor agonist SKF-81297 (Fig. 10, lane 4). In contrast, calphostin $\mathrm{C}$, an inhibitor of PKC, had no significant effect on the SKF-81297-mediated phosphorylation of STEP isoforms (data not shown).

\section{DISCUSSION}

A key finding of the present study is that a neuron-specific PTP, STEP, is subject to regulation via phosphorylation by the neurotransmitter dopamine via a cAMP-dependent protein kinase pathway. To our knowledge, this is the first demonstration that a PTP can be regulated by a neurotransmitter. Our initial observations indicated that both $\mathrm{STEP}_{61}$ and $\mathrm{STEP}_{46}$ could be phosphorylated 


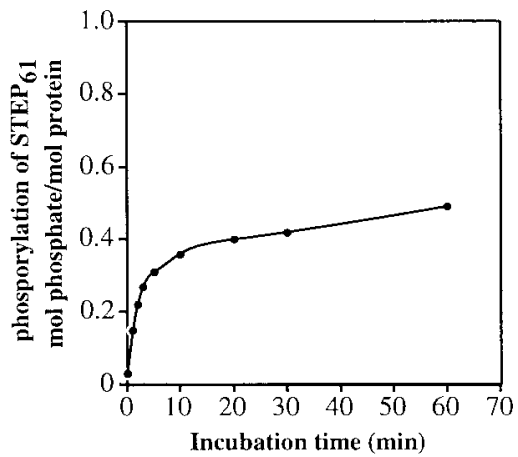

B
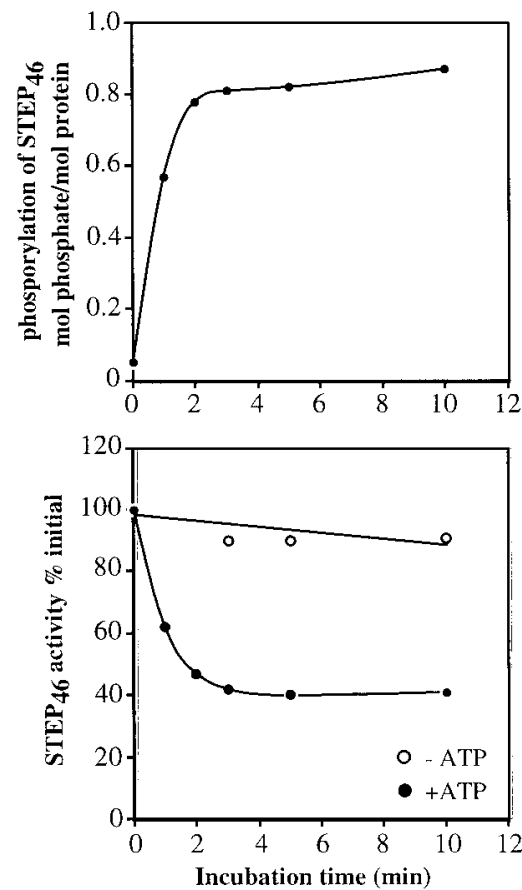

Figure 6. Phosphorylation and inactivation of $\mathrm{STEP}_{46}$ by PKA. STEP 61 $(A)$ and $\operatorname{STEP}_{46}(B, t o p)$ fusion proteins $(6 \mu \mathrm{M})$ were phosphorylated with PKA in the presence of $\left[\gamma^{-32} \mathrm{P}\right]$ ATP. Aliquots of the reactions were removed at the indicated time points, and the extent of phosphorylation was estimated by quantification of Cerenkov radiation. $B$, Bottom, STEP $_{46}$ was phosphorylated by PKA $(-)$ using unlabeled ATP. At each time point $(0,1$, $2,3,5$, and $10 \mathrm{~min}$ ), the reaction was terminated by addition of the PKA inhibitor PKI- $\alpha$, and STEP phosphatase activity was assayed by dephosphorylation of ${ }^{32} \mathrm{P}$-labeled myelin basic protein. Control experiments $(\bigcirc)$ were performed under identical conditions but without ATP. Results are plotted as a percent of the enzyme activity at zero time. The data represent the mean value from three independent experiments.

by endogenous PKA in striatal homogenates. Phosphorylation was blocked by a highly specific inhibitor of PKA, PKI- $\alpha$. Mutational analysis and phosphopeptide mapping indicated that Ser160 and Ser221 are the two major PKA phosphorylation sites present in $\mathrm{STEP}_{61}$. In $\mathrm{STEP}_{46}$, there is a single PKA phosphorylation site at Ser49 that is equivalent to Ser221 in $\mathrm{STEP}_{61}$. The sequences surrounding each serine residue are those of consensus PKA phosphorylation sites: RRQSVS for Ser160 and RRGSNV for Ser221 and Ser49 (Fig. 3A). Each contains two adjacent basic residues $\mathrm{N}$-terminal to and separated from the phosphorylated serine by a single amino acid.

Phosphorylation of $\mathrm{STEP}_{46}$ by PKA led to a significant decrease in its ability to dephosphorylate MBP in vitro. This inhibition of $\mathrm{STEP}_{46}$ activity, after phosphorylation, resulted from a decrease in the apparent affinity of the enzyme for its substrate. This result suggests that the phosphorylation site may reside in a region of the

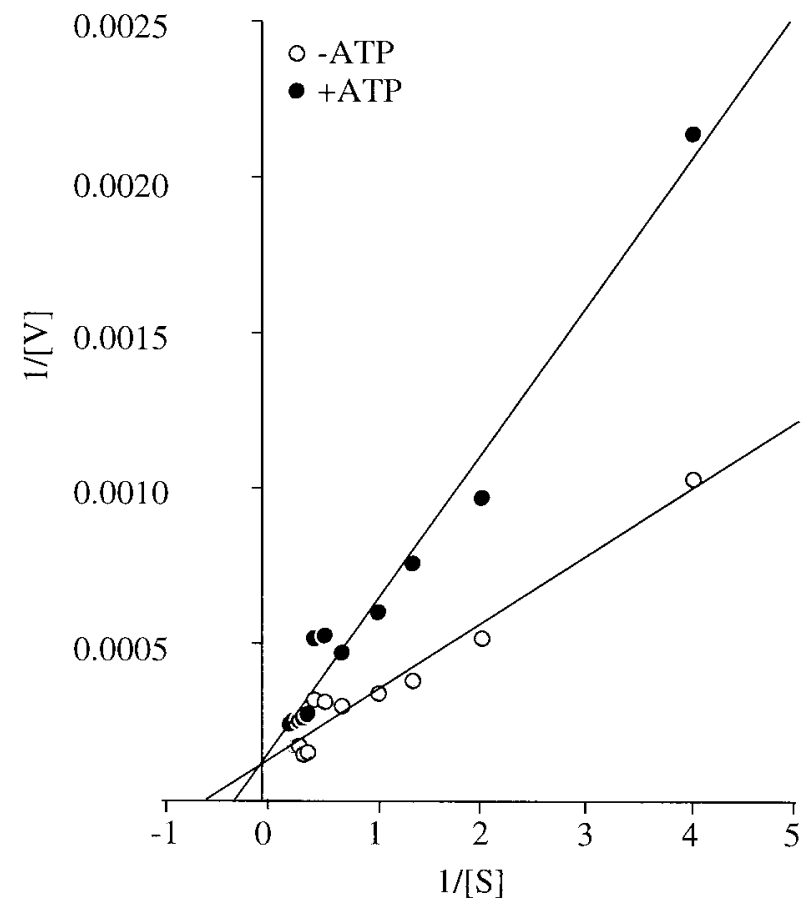

Figure 7. Lineweaver-Burk analysis of PKA phosphorylated and nonphosphorylated STEP ${ }_{46}$. STEP $_{46}$ was incubated with PKA in the absence or presence of ATP for $5 \mathrm{~min}$. The reaction was then terminated as described in Figure 6. Both nonphosphorylated $(\bigcirc)$ and phosphorylated $(\bullet)$ STEP $_{46}$ were then incubated with different concentrations of ${ }^{32} \mathrm{P}$-labeled myelin basic protein. The results are plotted as the reciprocal of enzyme activity (units per milligram) versus the reciprocal of substrate concentration (micromolar). Data presented represent the means from triplicate assays.

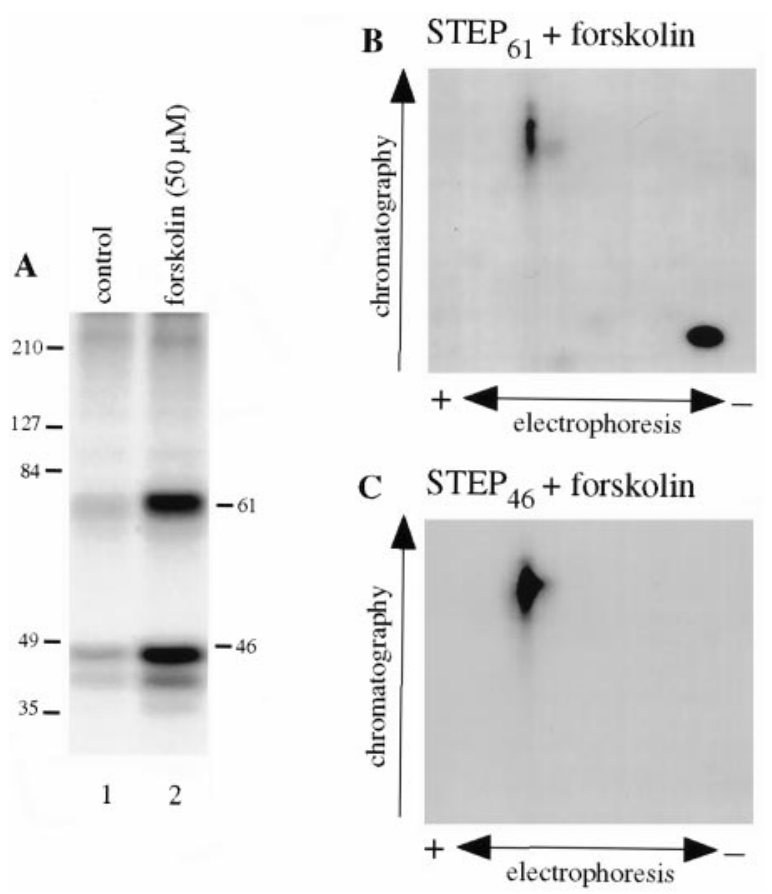

Figure 8. Phosphorylation and peptide mapping of STEP isoforms from striatal slices treated with forskolin. $A$, Striatal slices prelabeled with $\left.{ }^{32} \mathrm{P}\right]$ phosphate for $60 \mathrm{~min}$ were incubated with control buffer (lane 1) or forskolin $(50 \mu \mathrm{M}$; lane 2) followed by immunoprecipitation of STEP isoforms, SDS-PAGE analysis, and autoradiography. The autoradiogram shows incorporation of [ $\left.{ }^{32} \mathrm{P}\right]$ phosphate into STEP 61 and $\mathrm{STEP}_{46} . B, C, \mathrm{Gel}$ pieces containing ${ }^{32} \mathrm{P}$-labeled STEP ${ }_{61}(B)$ or $\mathrm{STEP}_{46}(C)$ were excised and subjected to tryptic phosphopeptide mapping and autoradiography as described in Materials and Methods. 
A

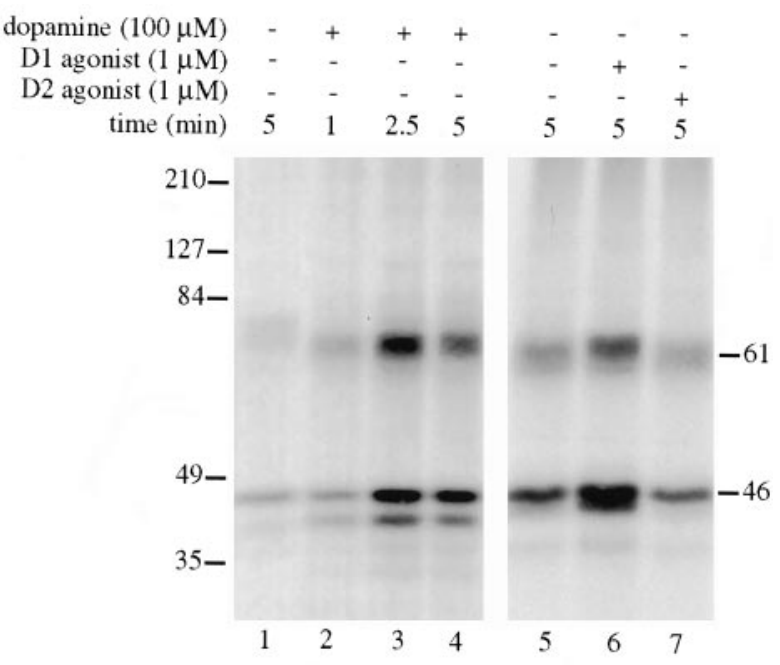

B dopamine $(100 \mu \mathrm{M})$

D1 agonist $(1 \mu \mathrm{M})$

D1 antagonist $(1 \mu \mathrm{M})$

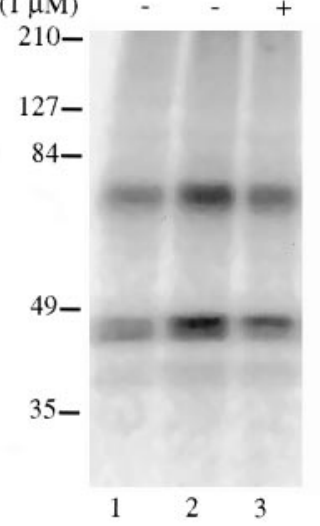

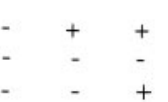
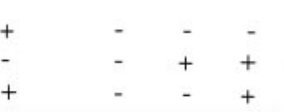

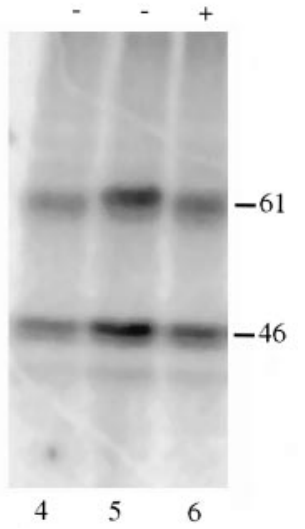

Figure 9. Effect of dopamine, the D1 receptor agonist, and the D2 receptor agonist on the phosphorylation of STEP isoforms from striatal slices. $A$, Striatal slices prelabeled with $\left[{ }^{32} \mathrm{P}\right]$ phosphate for $60 \mathrm{~min}$ were incubated with control buffer (lane 1), dopamine $(100 \mu \mathrm{M}$; lanes 2-4), the D1 receptor agonist SKF-81297 (1 $\mu \mathrm{M}$; lane 6$)$, or the D2 receptor agonist quinpirole (1 $\mu \mathrm{M}$; lane 7) for the indicated times, followed by immunoprecipitation of STEP isoforms, SDS-PAGE analysis, and autoradiography. $B$, Striatal slices prelabeled with $\left[{ }^{32} \mathrm{P}\right]$ phosphate were incubated with or without the D1 receptor antagonist $\mathrm{SCH}-23390(1 \mu \mathrm{M})$ for $15 \mathrm{~min}$ followed by incubation with either dopamine $(1 \mu \mathrm{M}$; lanes 2,3$)$ or the D1 receptor agonist SKF-81297 (1 $\mu \mathrm{M}$; lanes 5, 6 ) for $5 \mathrm{~min}$. STEP isoforms were then immunoprecipitated and analyzed by SDS-PAGE and autoradiography. The autoradiograms show incorporation of $\left[{ }^{32} \mathrm{P}\right]$ phosphate into $\mathrm{STEP}_{61}$ and $\mathrm{STEP}_{46}$. Each experiment was repeated at least three times. The molecular mass standards are indicated in kilodaltons on the left. The numbers on the right indicate the protein bands corresponding to $\mathrm{STEP}_{61}$ and $\mathrm{STEP}_{46}$.

enzyme involved in substrate binding and that the phosphorylated residue sterically hinders the enzyme-substrate interaction.

A similar assessment of STEP $_{61}$ activity after phosphorylation was prevented by several factors. These include the fact that STEP $_{61}$ is a membrane-bound protein, is less active than STEP $_{46}$, and is substoichiometrically phosphorylated by PKA in vitro. However, it is reasonable to predict that phosphorylation of Ser221 in $\mathrm{STEP}_{61}$, which is identical to Ser49 in $\mathrm{STEP}_{46}$, is likely to have a similar effect on its activity by interfering with its binding affinity for substrates. On the other hand, the significance of the phosphorylation of Ser160 in the juxtamembrane domain of STEP $_{61}$ remains unclear. This site is immediately adjacent to a PEST sequence, found in $\mathrm{STEP}_{61}$ but absent in $\mathrm{STEP}_{46}$. PEST sequences are found in a number of proteins and have been shown to be signals for proteolytic cleavage (Rogers et al., 1986). It has also been proposed that cleavage at PEST sequences may be stimulated by phosphor-

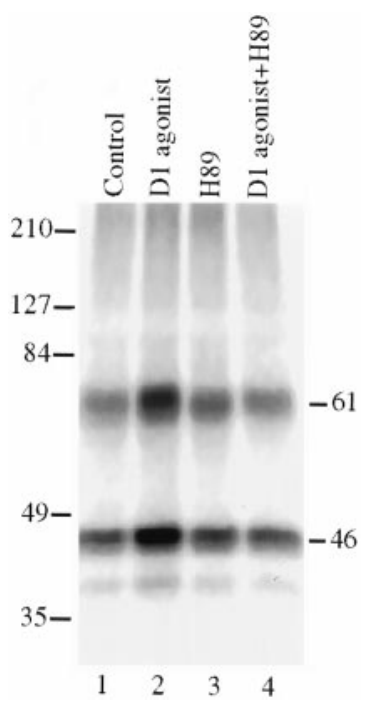

Figure 10. Effect of the PKA inhibitor H-89 on the D1 receptor-induced phosphorylation of STEP isoforms from striatal slices. Striatal slices were prelabeled with [ $\left.{ }^{32} \mathrm{P}\right]$ phosphate. They were then incubated with (lanes 3, 4) or without (lanes 1, 2) the PKA inhibitor H-89 $(1 \mu \mathrm{M})$ for $15 \mathrm{~min}$, followed by treatment with the D1 agonist SKF-81297 (1 $\mu \mathrm{M}$; lanes 2, 4$)$ for $5 \mathrm{~min}$. $\left.{ }^{32} \mathrm{P}\right]$ phosphate-labeled STEP isoforms were then analyzed as described in the legends to Figures 8 and 9. Each experiment was repeated at least three times.

ylation of a site within or adjacent to the PEST sequence (Rechsteiner, 1988, 1990). In this regard, we have established recently that STEP $_{61}$ is in fact proteolytically cleaved by a calciumdependent pathway to release a smaller molecular weight isoform $\left(\right.$ STEP $\left._{33}\right)$ (Nguyen et al., 1999). The exact position of the cleavage site must be determined by amino acid sequencing. However, based on the apparent mobility of the proteolytic fragment, the likely position lies close to the PEST sequence. Cleavage of STEP $_{61}$ also occurs in response to glutamate treatment of striatal neurons in

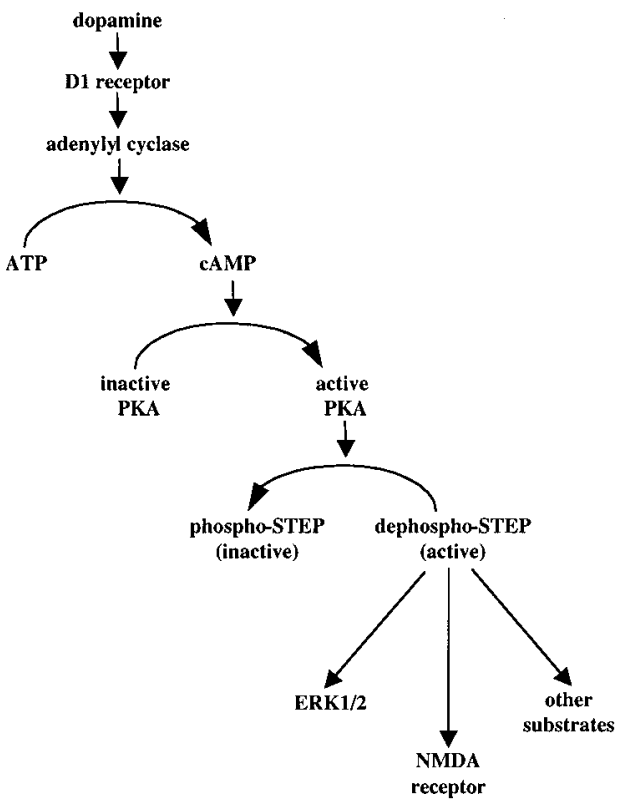

Figure 11. A working model for the physiological regulation of STEP phosphorylation via D1 receptor activation. Dopamine/D1 receptor activation leads to the phosphorylation of $\mathrm{STEP}_{46}$ on Ser49 (or $\mathrm{STEP}_{61}$ on Ser221), within the KIM domain, via the cAMP/PKA pathway. Phosphorylation results in the inhibition of STEP activity because of the loss in binding affinity for its substrate(s). In the nonphosphorylated form STEP can bind to and dephosphorylate its downstream effector proteins, which possibly include ERK1/2 and NMDA receptors. 
primary cell cultures (Nguyen et al., 1999) and in whole animals after transient hypoxia/ischemia to the brain (Gurd et al., 1999). Additional studies will be necessary to demonstrate that phosphorylation at Ser160 is in fact required for, or regulates, cleavage of STEP $_{61}$.

In vivo experiments on striatal slices further established the physiological significance of our biochemical findings. These experiments demonstrated that activation of D1 receptors by dopamine led to PKA-mediated phosphorylation of both STEP ${ }_{61}$ and STEP 46 in striatal slices. Moreover, they confirmed that in vivo there are two PKA phosphorylation sites in STEP $_{61}$ (Ser160 and Ser221) and a single site in $\mathrm{STEP}_{46}$ (Ser49). These observations suggest a potential role for STEP in mediating the effects of dopamine on the tyrosine phosphorylation of its target proteins. Although the present study did not address this question directly, our data combined with other recent findings indicate that there may be a relationship between the phosphorylation of STEP in response to dopamine treatment and the modulation of MAP kinase activity. In this regard, the 16-amino-acid-long KIM region, present in both STEP $_{61}$ and STEP $_{46}$, is also conserved in several related tyrosine phosphatases, including PTP-SL, HePTP, and PTP-ER (Fig. 3B) (Pulido et al., 1998; Karim and Rubin, 1999). This domain is crucial for the docking of each of these phosphatases with extracellular signal-related kinase1/2 (ERK1/2) (Zuniga et al., 1999). Binding of ERK1/2 to the KIM region of PTP-SL and HePTP leads to the dephosphorylation and inactivation of these MAP kinases and blocks their nuclear translocation. Phosphorylation by PKA of the conserved serine residue within the KIM domains of PTP-SL and HePTP abrogates their physical and functional association with ERK1/2 (Blanco-Aparicio et al., 1999; Saxena et al., 1999). In addition, the tyrosine phosphatase PTP-ER has been found to inactivate MAP kinases (Karim and Rubin, 1999). Our results demonstrate that PKA phosphorylates both STEP $_{46}$ and STEP $_{61}$ within the KIM domain, leading to inactivation of enzymatic activity. Phosphorylation of the KIM domain by PKA is therefore also likely to disrupt the interaction of STEP (and other proteins containing conserved KIM domains) with ERK1/2.

ERK1/2 are highly expressed in the nervous system and are localized primarily in the neuronal cell bodies and dendrites (Fiore et al., 1993; Ortiz et al., 1995). Activation of D1 receptors leads to the phosphorylation and activation of ERK1/2 (Vincent et al., 1998 ) in the striatal neurons. Application of D1 agonists also results in the phosphorylation of CRE-binding protein (CREB) and the induction of c-fos in these neurons (Das et al., 1997), and these effects are blocked by the PKA inhibitor $\mathrm{H}-89$. The present results now raise the possibility that STEP may be one of the components of the signal transduction pathway(s) involved in mediating the effects of the dopamine/D1 receptor on striatal neurons. Other studies suggest that stimulation of the D2 receptor can also lead to the activation of MAP kinase and CREB phosphorylation in the brain via intracellular $\mathrm{Ca}^{2+}$ elevation and protein kinase $\mathrm{C}$ activation (Yan et al., 1999). Additionally, coactivation of D1 and D2 receptors is known to trigger synergistic responses in the potentiation of immediate early genes in striatal neurons (Gerfen et al., 1995). Thus, it is likely that multiple routes exist for neuronal activity-dependent stimulation of ERK1/2 and CREB that would be expected to result in the activation of different downstream targets and functional responses.

Recent studies suggest that tyrosine phosphorylation of NR2 subunits in neuronal cells plays a critical role in the modulation of NMDA channel activity (Wang and Salter, 1994; Rostas et al., 1996; Oh et al., 1998). Behaviorally, tyrosine phosphorylation of NR2B subunits has been implicated in various forms of synaptic plasticity (Rossenblum et al., 1997) and the induction and maintenance of long-term potentiation (Rossenblum et al., 1996; Rostas et al., 1996). Ablation of the nigrostriatal dopamine system in rats by 6-hydroxydopamine has also been shown to enhance the tyrosine phosphorylation of striatal NR2B subunits (Menegoz et al., 1995). However, a functional role of protein tyrosine phosphatases in regulating NMDA channel activity is yet to be established. Iden- tification of such protein tyrosine phosphatases may help expand our understanding of NMDA channel activity-dependent signaling in neurons. A related study indicates that a protein tyrosine phosphatase is associated with the NMDA receptor complex and that its activation significantly downregulates the channel activity (Wang et al., 1996). Because STEP is preferentially expressed in striatal neurons receiving glutamatergic synaptic input (Lombroso et al., 1993), is colocalized in the immediate vicinity of these receptors within the striatal postsynaptic densities (Oyama et al., 1995), and coimmunoprecipitates with NMDA receptors (Askalan et al., 1997), it has been considered a possible candidate for modulating NMDA receptor activity either directly or indirectly. Using wholecell patch-clamp recordings, Pelkey et al. (1998) demonstrated that STEP reduced NMDA channel activity. In contrast, intracellular application of the anti-STEP monoclonal antibody 23E5 enhanced the NMDA channel activity by $\sim 50 \%$. Because the STEP antibody had been raised against a peptide sequence that lies within the KIM domain, it is possible that the antibody interferes with STEPsubstrate interactions by blocking accessibility to the KIM domain. Thus PKA-mediated phosphorylation of STEP could inhibit dephosphorylation of NR2 subunits and influence NMDA receptorsignaling pathways in medium spiny neurons.

In conclusion, this study provides new insight into the signaling mechanism(s) underlying D1 receptor-mediated signaling in striatal neurons. A working model (Fig. 11) for this signaling pathway, which incorporates the results reported here and other established observations, illustrates that stimulation of D1 receptors leads to activation of PKA and phosphorylation of STEP isoforms within their respective KIM domains. Because the KIM domain is necessary for protein-protein interactions between STEP and downstream effector proteins, phosphorylation would be predicted to decrease the affinity of STEP for its substrate(s) in striatal neurons, which possibly includes ERK1/2 and NMDA receptors.

\section{REFERENCES}

Askalan R, Nguyen TH, Salter M, Lombroso PJ (1997) The tyrosine phosphatase STEP is associated with NMDA receptors from rat spinal cord. Soc Neurosci Abstr 687:7.

Blanco-Aparicio C, Torres J, Pulido R (1999) A novel regulatory mechanism of MAP kinases activation and nuclear translocation mediated by PKA and the PTP-SL tyrosine phosphatase. J Cell Biol 147:1129-1135.

Boulanger LM, Lombroso PJ, Raghunathan A, During MJ, Wahle P, Naegele JR (1995) Cellular and molecular characterization of a brainenriched protein tyrosine phosphatase. J Neurosci 15:1532-1544.

Bult A, Zhao F, Dirkx R, Sharma E, Lukacsi E, Solimena M, Naegele JR, Lombroso PJ (1996) A new member of a family of brain-enriched PTPs is localized to the ER. J Neurosci 16:7821-7831.

Bult A, Zhao F, Dirkx R, Raghunathan A, Solimena M, Lombroso PJ (1997) STEP: a family of brain enriched PTPs. Alternative splicing produces transmembrane, cytosolic and truncated isoforms. Eur J Cell Biol 72:337-344.

Cepeda C, Levine M (1998) Dopamine and $N$-methyl-D-aspartate receptor interactions in the neostriatum. Dev Neurosci 20:1-18.

Cepeda C, Buchwald N, Levine M (1993) Neuromodulatory actions of dopamine in the neostriatum are dependent upon the excitatory amino acid receptor subtypes activated. Proc Natl Acad Sci USA 90:9576-9580.

Chen S, Leonard JP (1996) Protein tyrosine kinase-mediated potentiation of currents from cloned NMDA receptors. J Neurochem 67:194-200.

Chernoff J (1999) Protein tyrosine phosphatases as negative regulators of mitogenic signaling. J Cell Physiol 180:173-181.

Cooke MP, Perlmutter RM (1989) Expression of a novel form of the fyn proto-oncogene in hematopoietic cells. New Biol 1:66-74.

Das S, Grunert M, Williams L, Vincent SR (1997) NMDA and D1 receptors regulate the phosphorylation of CREB and the induction of c-fos in striatal neurons in primary cultures. Synapse 25:227-233.

Desai CJ, Sun Q, Zinn K (1997) Tyrosine phosphorylation and axon guidance: of mice and flies. Curr Opin Neurobiol 7:70-74.

Dutta R, Stoker A (1998) Protein tyrosine phosphatases and neural development. BioEssays 20:463-472.

Fiore RS, Bayer VE, Pelech SL, Posada J, Cooper JA, Baraban JM (1993) p42 mitogen-activated protein kinase in brain: prominent localization in neuronal cell bodies and dendrites. Neuroscience 55:463-472.

Fischer EH, Charbonneau H, Tonks NK (1991) Protein tyrosine phosphatases: a diverse family of intracellular and transmembrane enzymes. Science 253:401-406.

Fonnum F, Storm-Mathisen J, Divac I (1981) Biochemical evidence for glutamate as neurotransmitter in corticostriatal and corticothalamic fibers in rat brain. Neuroscience 6:863-873.

Freund TF, Powell JF, Smith AD (1984) Tyrosine hydroxylase- 
immunoreactive boutons in synaptic contact with identified striatonigral neurons, with particular reference to dendritic spines. Neuroscience 13:1189-1215.

Gerfen CR, Keefe KA, Gauda EB (1995) D1 and D2 dopamine receptor function in the striatum: coactivation of D1- and D2-dopamine receptors on separate populations of neurons results in potentiated immediate early gene response in D1-containing neurons. J Neurosci 15:8167-8176.

Greengard P, Allen PB, Nairn AC (1999) Beyond the dopamine receptor: the DARPP-32/protein phosphatase-1 cascade. Neuron 23:435-447.

Gurd JW, Bissoon N, Nguyen TH, Lombroso PJ, Beesley PW, Rider CC, Vannucci SJ (1999) Hypoxia-ischemia in perinatal rat brain induces the formation of a low molecular weight isoform of the protein tyrosine phosphatase, STEP. J Neurochem 73:1990-1995.

Hunter T (1995) Protein kinases and phosphatases: the yin and yang of protein phosphorylation and signaling. Cell 80:225-236.

Hunter T (1998) The phosphorylation of proteins on tyrosine: its role in cell growth and disease. Philos Trans R Soc Lond B Biol Sci 353:583-605.

Karim FD, Rubin GM (1999) PTP-ER, a novel tyrosine phosphatase, functions downstream of Ras1 to downregulate MAP kinase during Drosophila eye development. Mol Cell 3:741-750.

Kohr G, Seeburg PH (1996) Subtype-specific regulation of recombinant NMDA receptor-channels by protein tyrosine kinases of the src family. J Physiol (Lond) 492:445-452.

Kotter R (1994) Postsynaptic integration of glutamatergic and dopaminergic signals in the striatum. Prog Neurobiol 44:163-196.

Laemmli UK (1970) Cleavage of structural proteins during the preassembly of the head of bacteriophage T4. Nature 227:680-685.

Lombroso PJ, Murdoch G, Lerner M (1991) Molecular characterization of a protein-tyrosine-phosphatase enriched in striatum. Proc Natl Acad Sci USA 88:7242-7246.

Lombroso PJ, Naegele JR, Sharma E, Lerner M (1993) A brain-enriched protein tyrosine phosphatase is present in dopaminoceptive neurons. J Neurosci 13:3064-3074.

Lu YM, Roder JC, Davidow J, Salter MW (1998) Src activation in the induction of LTP in CA1 hippocampal neurons. Science 279:1363-1367.

Menegoz M, Lau LF, Herve D, Huganir RL, Girault JA (1995) Tyrosine phosphorylation of NMDA receptor in rat striatum: effect of 6-OHDA dopamine lesions. NeuroReport 7:125-128.

Naegele JR, Lombroso PJ (1994) Protein tyrosine phosphatases in the central nervous system. Crit Rev Neurobiol 9:115-124.

Nairn A, Greengard P (1987) Purification and characterization of $\mathrm{Ca} 2+$ / calmodulin-dependent protein kinase I from bovine brain. J Biol Chem 262:7273-7281.

Nguyen TH, Xu Y, Gurd J, Lombroso PJ (1999) $\mathrm{Ca}^{++}$-dependent cleavage of striatal enriched tyrosine phosphatase (STEP). J Neurochem 73:1995-2001.

Oh JD, Russell DS, Vaughan CL, Chase TN (1998) Enhanced tyrosine phosphorylation of striatal NMDA receptor subunits: effect of dopaminergic denervation and L-DOPA administration. Brain Res 30:150-159.

Ortiz J, Harris HW, Guitart X, Terwilliger RZ, Haycock JW, Nestler EJ (1995) Extracellular signal-regulated protein kinases (ERKs) and ERK kinase $(\mathrm{MEK})$ in brain: regional distribution and regulation by chronic morphine. J Neurosci 15:1285-1297.

Oyama T, Goto S, Nishi T, Sato K, Yamada K, Yoshikawa M, Ushio Y (1995) Immunocytochemical localization of the striatal enriched protein tyrosine phosphatase in the rat striatum: EM study. Neuroscience 69:869-880.

Pelkey KA, Askalan R, Nguyen TH, Salter MW, Lombroso PJ (1998) Regulation of the NMDA receptors by the protein tyrosine phosphatase, STEP, in spinal cord dorsal horn neurons. Soc Neurosci Abstr 24:724.

Pulido R, Zuniga A, Ulrich A (1998) PTP-SL and STEP protein tyrosine phosphatases regulate the activation of the extracellular signal-regulated kinases ERK1 and ERK2 by association through a kinase interaction motif. EMBO J 17:7337-7350.
Qu Z, Moritz E, Huganir RL (1990) Regulation of tyrosine phosphorylation of the nicotinic acetylcholine receptor at the rat neuromuscular junction. Neuron 2:367-378.

Rechsteiner M (1988) Regulation of enzyme levels by proteolysis: the role of PEST regions. Adv Enzyme Regul 27:135-151.

Rechsteiner M (1990) PEST sequences are signals for rapid intracellular proteolysis. Semin Cell Biol 1:433-440.

Rogers S, Wells R, Rechsteiner M (1986) Amino acid sequences common to rapidly degraded proteins: the PEST hypothesis. Science 234:364-368.

Rossenblum K, Dudai Y, Levin GR (1996) Long-term potentiation increases tyrosine phosphorylation of the $N$-methyl-D-aspartate receptor subunit $2 \mathrm{~B}$ in rat dentate gyrus in vivo. Proc Natl Acad Sci USA 93:10457-10460.

Rossenblum K, Berman DE, Hazvi S, Lamprecht R, Dudai Y (1997) NMDA receptor and the tyrosine phosphorylation of its $2 \mathrm{~B}$ subunit in taste learning in the rat insular cortex. J Neurosci 17:5129-5135.

Rostas JAP, Brent VA, Voss K, Errington ML, Bliss TVP, Gurd JW (1996) Enhanced tyrosine phosphorylation of the 2B subunit of the $N$-methyl-D-aspartate receptor in long term potentiation. Proc Natl Acad Sci USA 93:10452-10456.

Saxena M, Williams S, Tasken K, Mustelin T (1999) Crosstalk between cAMP-dependent kinase and MAP kinase through a protein tyrosine phosphatase. Nat Cell Biol 1:305-311.

Sharma E, Zhao F, Bult A, Lombroso PJ (1995) Isolation and characterization of STEP20: an isoform of a family of brain-enriched protein tyrosine phosphatases. Mol Brain Res 32:87-93.

Smart TG (1997) Regulation of excitatory and inhibitory neurotransmitter-gated ion channels by protein phosphorylation. Curr Opin Neurobiol 7:358-367.

Snyder GL, Fienberg AA, Huganir RL, Greengard P (1998) A dopamine/D1 receptor/protein kinase A/dopamine- and cAMP-regulated phosphoprotein $\left(M_{\mathrm{r}} 32 \mathrm{kDa}\right) /$ protein phosphatase-1 pathway regulates dephosphorylation of the NMDA receptor. J Neurosci 18:10297-10303.

Somogyi P, Bolam JP, Smith AD (1981) Monosynaptic cortical input and local axon collaterals of identified striatonigral neurons. A light and electron microscopic study using the Golgi-peroxidase transportdegeneration procedure. J Comp Neurol 195:567-584.

Tonks NK, Neel BG (1996) From form to function: signaling by protein tyrosine phosphatases. Cell 87:365-368.

Vactor DV (1998) Protein tyrosine phosphatases in the developing nervous system. Curr Opin Cell Biol 10:174-181.

Vincent SR, Sebben M, Dumuis A, Bockaert J (1998) Neurotransmitter regulation of MAP kinase signaling in striatal neurons in primary culture. Synapse 29:29-36.

Wagner KR, Mei L, Huganir RL (1991) Protein tyrosine kinases and phosphatases in the nervous system. Curr Opin Neurobiol 1:65-73.

Walton KM, Dixon JE (1993) Protein tyrosine phosphatase. Annu Rev Biochem 62:101-120.

Wang Y, Salter M (1994) Regulation of NMDA receptors by tyrosine kinases and phosphatases. Nature 369:233-235.

Wang Y, Yu X, Salter M (1996) Ca(2+)-independent reduction of $N$-methyl-D-aspartate channel activity by protein tyrosine phosphatase. Proc Natl Acad Sci USA 93:1721-1725.

Winslow JW, Moran P, Valverde J, Shih A, Yuan JQ (1995) Cloning of AL-1, a ligand for an Eph-related tyrosine kinase receptor involved in axon bundle formation. Neuron 14:973-981.

Yan Z, Feng J, Fienberg AA, Greengard P (1999) D2 dopamine receptors induce mitogen-activated protein kinase and cAMP response elementbinding protein phosphorylation in neurons. Proc Natl Acad Sci USA 96:11607-11612.

Zuniga A, Torres J, Ubeda J, Pulido R (1999) Interaction of mitogenactivated protein kinases with the kinase interaction motif of the tyrosine phosphatase PTP-SL provides substrate specificity and retains ERK2 in the cytoplasm. J Biol Chem 274:21900-21907. 